\title{
Iron isotopes trace primordial magma ocean cumulates melting in the Earth's upper mantle
}

HELEN M WILLIAMS ${ }^{1}$, SIMON MATTHEWS ${ }^{2}$, HANIKA $\mathrm{RIZO}^{3}$ AND OLIVER SHORTTLE ${ }^{1}$

${ }^{1}$ University of Cambridge

${ }^{2}$ University of Iceland

${ }^{3}$ Carleton University

Presenting Author: hmw20@cam.ac.uk

The differentiation of the Earth $\sim 4 \mathrm{Ga}$ is believed to have culminated in magma ocean crystallization, crystal-liquid separation and the generation of mineralogically distinct reservoirs in the mantle [e.g., 1]. However, the magma ocean model remains difficult to validate due to the scarcity of geochemical tracers of lower mantle mineralogy. The Fe isotope compositions $\left(\delta^{57} \mathrm{Fe}\right)$ of ancient mafic rocks can be used to reconstruct the mineralogical evolution of their mantle source regions [2-3]. We present Fe isotope data for well-characterised 3.7 Ga metabasalts from the Isua Supracrustal Belt [4-5]. The $\delta^{57} \mathrm{Fe}$ signatures of these samples are elevated relative to modern equivalents and define striking correlations with fluid-immobile trace elements and tungsten isotope anomalies $\left(\mu^{182} \mathrm{~W}\right)$. Phase equilibria models demonstrate [e.g., 6] that these features can be explained by melting of a magma ocean cumulate component in the upper mantle. Similar processes may operate today, as evidenced by the $\delta^{57} \mathrm{Fe}$ and $\mu^{182} \mathrm{~W}$ heterogeneity of modern oceanic basalts [7-8].

[1] Labrosse, S. et al., (2007). Nature; [2] Williams, H. M. et al., (2012). EPSL; [3] Williams, H. M., \& Bizimis, M. (2014). EPSL; [4] Rizo, H. et al., (2011). EPSL; [5] Rizo, H. et al., (2016). GCA; [6] Soderman, C. R. et al., (2021). GCA; [7] Mundl, A. et al., (2017). Science; [8] Nebel, O. et al., (2019). EPSL 